\title{
Multidisciplinary training program for the promotion of physical activity and other healthy habits in adolescents: justification, design and methodology of PAP study
}

Pedro Antonio Sánchez-Miguel ( $\nabla$ pesanchezm@unex.es )

https://orcid.org/0000-0002-1660-535X

Mikel Vaquero-Solís

Universidad de Extremadura

David Sánchez-Oliva

Universidad de Extremadura

Juan José Pulido González

Universidad de Extremadura

Miguel Angel Tapia Serrano

Universidad de Extremadura https://orcid.org/0000-0003-2954-2375

\section{Study protocol}

Keywords: overweight, obesity, physical activity and physical activity programme

Posted Date: November 1st, 2019

DOI: https://doi.org/10.21203/rs.2.16360/v1

License: (c) (i) This work is licensed under a Creative Commons Attribution 4.0 International License.

Read Full License 


\section{Abstract}

Overweight and obesity are one of the most important health problems worldwide. Physical inactivity is indicated as one of the most determining factors of overweight and obesity. The Self-Determination Theory points out the importance of motivation in the patterns related to physical activity. The aims of this study were to show the reasons for performing and the methods of a randomised controlled trial o evaluate the effectiveness of a multidisciplinary physical activity programme to promote physical activity levels in inactive school children and encourage healthy lifestyles, carried out under the SelfDetermination Theory postulates. The present paper presents a RCT for adolescents of 1 st and 2nd grades of Secondary Compulsory School. The multidisciplinary training program consists of two parts: the first part is cross-sectional, and the second part, the Physical Activity Program, is of a longitudinal nature. This project takes into account the socio-economic impact that a healthy lifestyle will generate, as well as its potential to apply the results and transfer them to the productive sector. This study is of great interest to the scientific community as it will provide relevant information on physical inactivity issues, sedentary lifestyle, generation of healthy habits and physical exercise.

\section{Background}

According to the World Health Organization (1) overweight and obesity are defined as an abnormal or excessive accumulation of fat that can be harmful to health, and they are one of the most important public health problems worldwide, generating biological and psychosocial disorders. Numerous studies worldwide (2) have developed interventions to promote healthy lifestyles in childhood and adolescence $(3,4)$.

Among the determining factors of high levels of overweight and obesity in youth population is physical inactivity (PI). $\mathrm{PI}$ is defined as decrease in body movement that produces decreased energy expenditure (5) and seems to be one of the main triggers of overweight and obesity registered in the recent studies worldwide (6). The WHO (1) places the PI as the fourth risk factor for death, and it is the cause of $6 \%$ of the deaths registered annually in the world and the main cause of some diseases (breast and colon cancer, diabetes, or heart disease). At the National and European levels, respectively, both the Center for Sociological Research (7) and the EU point out in their report that 35\% of adolescents between 9 and 17 years are insufficiently active and, that, as of age 15 , only half of them perform physical activity (PA).

Studies that have analyzed the consequences of PI reveal childhood and adolescence as key stages to attenuate the effects of overweight and obesity (8). A growing body of literature, arising from the SelfDetermination Theory (SDT; 9) has begun to note the influence of motivation in shaping PA patterns, contributing compelling evidence to support and understand the utility of motivation to increase PA (10). At the most basic level, SDT divides the types of motivations into intrinsic motivation (i.e., behavior as inherently enjoyable), extrinsic motivation (i.e., behavior as a means to an end), and amotivation (lack of motivation). Extrinsic motivations are further divided into categories on an underlying continuum reflecting the degree to which the source of the motivation is external (e.g., rewards/punishment) or 
internal (e.g., valuing its outcomes). The last great construct is amotivation, associated with behaviors that produce disorganized activity and associated with feelings of incompetence or frustration (9).

If continued PA can be consolidated as a habit, it will imply a series of benefits at the biological (11) and psychosocial level (12). Based on the above issues, this paper reports the reasons for and methods of a randomised controlled trial (RCT) to evaluate the effectiveness of a multidisciplinary Physical Activity Programme (PAP) to increase in inactive school children's PA levels and promote healthy lifestyles, developed following the SDT postulates.

\section{Methods}

\section{Design of the multidisciplinary training program}

The present paper is a RCT, corresponding to: Multidisciplinary Training Program for the Promotion of Physical Activity and Other Healthy Habits in Inactive Adolescents. The present paper is a RCT, corresponding to: Multidisciplinary Training Program for the Promotion of Physical Activity and Other Healthy Habits in Inactive Adolescents. The Trial registration: ClinicalTrials.gov ID: NCT03974607. Registered 19 August 2019 - Retrospectively registeres, https://cutt.ly/gerOXbg. This research is intended for adolescents enrolled in $1^{\text {st }}$ and $2^{\text {nd }}$ grade of Secondary Compulsory School. The multidisciplinary training program consists of two parts: the first one is cross-sectional, and the second part is the randomised longitudinal. Each of these parts is subdivided into different phases (Figure 1). The first part is subdivided into three phases: contact with the school, recruitment of the participants, and evaluation of the participants. The PAP is subdivided into four phases: recruitment of the participant's school for PAP, selection of participants, evaluation of the participants, and training of periodization.

The study will be carried out following the ethical guidelines of the Declaration of Helsinki, and its 2013 modification, and approved by the Human Research Ethics Committee of the University of Extremadura. Sample selection will be random, inviting the schools that participate in the first part from participating second part: PAP. The order of the reserve schools will also be drawn to prepare a list to replace those institutions whose directors refuse to participate.

To minimize the risks during the development of the study, the contraindications of the protocols marked by each evaluation test will be discarded. If a problem arises during the study, participants will be referred for a medical evaluation and, if necessary, they will be removed from the study. The present investigation will contract a civil liability insurance that will cover the participants, the responsibility of the researcher and of any person involved in the study, provided that there is adequate adherence to the protocol.

Figure1. Programme design

\section{Trial Status}


The second part of the PAP, specificaly in the begining of phase 3 of the intervention programme. Therefore, it has been begun the contact with the participant's schools of the first part. Recruitment is expected to begin on September 31, 2019 and that it ends on October 18, 2019. Thereafter, the development of the PAP will begin.

\section{Phase 1: Contact with the school}

A random selection of the different schools of the community of Extremadura will be made, up to a maximum of 23 schools. Also, 23 reserve schools will be randomly selected, in case the directors of the former school reject participation. This list will be arranged ordinally. The schools will be contacted, within a maximum period of one week, the research team and project technicians will contact the school directors via e-mail to confirm their interest in participating in the study. They will be given a period of fifteen days to respond. If they do not respond, they will be contacted by phone to present the project. If they do not accept participation in the study, we will proceed to contact the corresponding school of the reservation list, following the same procedure. If, on the contrary, they agree to participate, within a period of one week, visits to hand in the package of questionnaires will be programmed with the school director, and anthropometric and physical evaluation tests will be performed. To carry out these tests, the researchers will travel to the corresponding school to conduct the measurements. All measurements will be performed by the same research team, and each member will specialize in one test, to reduce possible measurement errors.

\section{Phase 2: Recruitment of the participants}

Once the schools have been randomised, all the students of the $1^{\text {st }}$ and $2^{\text {nd }}$ Secondary Compulsory Education Schools that accept taking part in the study will be allowed to participate. All students who wish to participate must submit two authorizations, one signed by their parents or tutors, and the other signed by the participants themselves, accepting participation in the study. Thus, we will avoid those cases in which the parent or tutor accepts participation in the study, but the adolescent refuses. The following inclusion criteria will be established: collaboration of the school after the draw, students' age ranging from 12 to 14 years ( $1^{\text {st }}$ and $2^{\text {nd }}$ grade of Secondary Compulsory Education) and delivering the informed consent signed by a parent or guardian and the participant.

\section{Phase 3: Evaluation of the participants.}

The variables and instruments to be used for the collection of cross-sectional data during the first part of the study are shown below (Table 1). 
Self-reported PA level. The PA level will be assessed with the PA Questionnaire for Adolescents (PAQ-A) (13). This is a self-administered, 7-day recall instrument, with 9 items scored on a five-point scale. The PAQ-A provides a final composite activity score composed of the mean of the 9 items. This questionnaire has been shown to be valid and reliable $(13,14)$. Extracurricular PA is assessed with the Finnish PA Index (15). It consists of 5 items concerning frequency and intensity of extracurricular PA and participation in organized sports. Using these five items, a PA index is calculated.

Self-reported Sedentary Behavior.Self-reported sedentary behavior will be assessed using the Youth Leisure-Time Sedentary Behavior Questionnaire. The Spanish version of the YSBQ for adolescents was used to assess the amount of time spent in 16 behaviours that were proposed previously by CabanasSánchez et al. (16): (i) watching TV/videos, (ii) playing computer/video games, (iii) internet surfing, (iv) doing homework/studying without a computer, (v) doing homework/studying with a computer, (vi) reading for fun, (vii) talking on the telephone, (viii) listening to music, (ix) sitting and talking with family and friends, (x) sitting to rest, (xi) hanging out, (xii) playing exercise videogames, (xiii) doing behavioural hobbies, (xiv) doing cognitive hobbies, (xv) travelling on motorized transport, and (xvi) doing sports/exercise. The items are completed separately for weekdays and weekends, referring to the past week. Response options are: none, 30 minutes, 1 hour, 1 and a half hours, 2 hours, 2 and a half hours, 3 hours, 4 hours, and 5 hours or more. Moreover, we created 6 comparative scales regarding how long participants spend (i) watching TV/videos, (ii) playing computer/video games, (iii) internet surfing, (iv) doing homework/studying and (v) doing sports/exercise, and (vi) sitting/lying in comparison with their peers of the same age and sex. An adjustment to leisure time taking into account sleep hours, school time, prevalence of each sedentary behaviour and physical activities was applied before performing the analyses. The average time in $\mathrm{min} /$ day for each behaviour was calculated as follows: [(weekday sedentary behaviour $* 5)+($ weekend sedentary behaviour $* 2) / 7$ ]. The questionnaire has shown a good reliability and adequate validity to assess sedentary behaviour in youth.

Body Image. To evaluate the dimension of body image, the Body Image Dimensional Assessment (BIDA) questionnaire (17) will be used. This is a silhouette-based scale that uses neutral figural stimuli to assess the subjective and affective dimensions of body image. This self-report scale that consists of 4 questions referring to 4 figures on a scale ranging from 1.8 to 5.2 (range 3.4). The four silhouettes are not gender-, or ethnic-, or age-related, to focus the

observer's attention on body shape: 1) Which figure do you think you currently look like? 2) Which is your ideal figure? 3) Which is the most attractive figure for the opposite sex? and 4) How do most people of your own sex and age look like?

Mediterranean Diet Quality Index. This instrument provides a Mediterranean Diet Quality Index in children and adolescents (KIDMED). The development of the KIDMED index will be based on principles sustaining Mediterranean eating patterns as well as those that undermine it (18). This questionnaire consists of 16 yes/no questions, 12 with a positive connotation and four with a negative connotation with respect to the Mediterranean Diet (MeD). Positive questions are assigned a value of +1 : (e.g., fruit or fruit juice daily, 
second fruit every day, etc.). Negative questions are assigned a value of -1 (e.g., consumption of fast foods more than once a week, skipping breakfast, etc.). The index of adherence to the MeD is calculated as the sum of all the responses and ranges from 0 to 12. Levels of adherence are classified into three groups: poor adherence (0-3), average adherence (4-7), and good adherence (8-12) to the MeD (18). Poor adherence is categorized as "Poor Diet" and average adherence and good adherence are categorized as "Average Diet" and "Optimal Diet".

\section{Health-related fitness}

Health-related fitness is assessed by field-based tests and self-reports using the ALPHA Fitness test battery (19). The extended version of the ALPHA health-related fitness test battery includes the following tests: (i) weight and height and body mass index (BMl: weight $(\mathrm{kg}) /$ heigth $^{2}(\mathrm{~cm})$ ); (ii) skinfold thickness (triceps and subscapular) to assess body composition; (iii) waist circumference; (iv) neck circumference (not included in the ALPHA Fitness battery) to assess body composition, (vi) the 20-m shuttle run test to assess cardiorespiratory fitness; (ii) handgrip strength; and (iii) standing long jump to assess musculoskeletal fitness; and (iv) the $4 \times 10 \mathrm{~m}$ shuttle run test to assess motor fitness.

Weight and Height. Weight is recorded to the nearest $0.1 \mathrm{~kg}$ using an electronic scale (model SECA 877) with participants dressed in lightweight clothing and without shoes. Height is measured to the nearest 1 $\mathrm{mm}$ using a telescopic height-measuring instrument. BMI was calculated as weight $(\mathrm{kg}) / \mathrm{height}\left(\mathrm{m}^{2}\right)$. Anthropometric measures are performed twice and the average is recorded.

Skinfold. Triceps and subscapular skinfold thickness are measured on the non-dominant side of the body with a Holtain caliper (range, 0 to $40 \mathrm{~mm}$; precision, $0.2 \mathrm{~mm}$ ). The triceps is raised in a vertical fold halfway between the acromion process and the superior head of the radius, on the back of the arm. The subscapular skinfold is measured about $20 \mathrm{~mm}$ below the inferior angle of the scapula and $45^{\circ}$ to the lateral side of the body. It is performed according to Lohman's anthropometric standardization reference manual (20). Triceps and subscapular skinfold thickness are measured twice, but not consecutively, and mean of the two measurements is used in the analyses. Percentage Body Fat (BF \%) will be calculated from triceps and subscapular skinfold thicknesses, using the equations developed by Slaughter et al. (21).

Waist Circumference. Waist circumference is measured with a non-elastic tape measure (SECA 200; range, 0 to $150 \mathrm{~cm}$; precision, $1 \mathrm{~mm}$ ), at the level of the natural waist, on a horizontal plane, which is the narrowest part of the torso, as seen from the front. In some obese participants, it is difficult to identify the waist circumference; therefore, this measurement is performed in the midpoint between the superior iliac spine and the costal edge in the midaxillary line (22). The measurements are taken at the end of a normal expiration, without the tape compressing the skin. The measurements are carried out twice, but not consecutively, and mean of the two measurements is used in the analyses.

Neck Circumference. Neck circumference (NC) is assessed with the participants standing in an erect position, with arms hanging freely and the head aligned in the Frankfort horizontal plane. The upper 
border of a non-elastic tape measure (SECA 200; range, $0-150 \mathrm{~cm}$; precision, $1 \mathrm{~mm}$ ) is placed just below the laryngeal prominence and applied perpendicularly to the long axis of the neck.

Cardiorespiratory fitness.Cardiorespiratory fitness (CRF) is evaluated with the $20-\mathrm{m}$ shuttle run test. The participants are required to run between two lines $20 \mathrm{~m}$ apart, while keeping pace with audio signals emitted from a pre-recorded CD. The initial speed is $8.5 \mathrm{~km} / \mathrm{h}$, and is increased by $0.5 \mathrm{~km} / \mathrm{h}$ per minute (one minute equals one stage). Participants are instructed to run in a straight line, to pivot on completing a shuttle, and to pace themselves in accordance with the audio signals. The test concludes when the participant fails to reach the end lines concurrent with the audio signals on two consecutive occasions, or when the subject stops because of fatigue. Participants are encouraged to keep running as long as possible throughout the test. The test is performed once, and the last completed stage or half-stage at which the subject dropped out is scored. A gymnasium or space large enough to mark out a $20-\mathrm{m}$ track will be used to perform the test.

Handgrip Strength Test. A hand dynamometer with adjustable grip (TKK 5101 Grip D; Takey, Tokio, Japan) will be used for this test. This dynamometer presents a high validity and reliability when compared with calibrated known weights (23). The participant squeezes gradually and continuously for at least two seconds, performing the test with the right and left hands in turn, and with the elbow in full extension as described elsewhere (23). The grip-span of the dynamometer is adjusted according to the hand size to determine the maximum handgrip strength using the equations specifically developed for children (24) and adolescents (25). The test is performed twice and the maximum score for each hand is recorded in kilograms. The sum of the scores achieved by left and right hands is used in the analysis.

Lower Limb Strength. Lower limb strength is evaluated with the standing long jump test. The subject will place behind the initial line and feet shoulder width apart. The participant jumps as far forward as possible on a non-slip hard surface. The test is performed twice, and the best score is recorded in centimeters.

$4 \times 10 \mathrm{~m}$ shuttle run test. The $4 \times 10$-m shuttle run is an adaptation of the $5 \times 10$-m shuttle run test included in the EUROFIT battery (26), maintaining the same characteristics. Velocity, agility and coordination are assessed in this test. The participant will run $10 \mathrm{~m}$ four times (back and forth) as fast as possible. The test is performed twice and the best score is recorded in hundredths of a second.

Table 1. Variables and instruments of the multidisciplinary program 


\begin{tabular}{ll}
\hline & Lifestyle variables \\
\hline Perceived PA level & PAQ-A (13) \\
\hline Self-reported Sedentary Behavior & YSBQ (27) \\
\hline Body Image Dimension & BIDA (17) \\
\hline Mediterranean Diet Quality Index in children and adolescents & KIDMED (18) \\
\hline \multicolumn{2}{c}{ Health-related fitness (ALPHA Fitness, Ruíz et al. (28)) } \\
\hline Weight and Height & Weighing scales (SECA 877) \\
BMI & Weight/Height ${ }^{2}$ \\
\hline Skinfold: subscapular and tricipital & Plicometer Holstein \\
\hline Body Fat & Equations developed by Slaughter et al. (21) \\
\hline Waist Circumference & Non-elastic tape SECA 200 \\
\hline Neck Circumference & \\
\hline Cardiorespiratory Fitness & 20-m shuttle run test \\
\hline Handgrip Strength Test & Dynamometry TKK 5101 \\
\hline Lower Limb Strength & Standing long jump test \\
\hline Velocity, Agility and Coordination & $4 \times 10-m$ shuttle run test \\
\hline
\end{tabular}

Note. $\mathrm{PA}=$ Physical Activity; $\mathrm{BMI}=$ Body Mass Index.

\section{Second Part: PAP}

As we can see in the schedule (Figure 2), the PAP will consist of 4 phases: phase 1) recruitment of the school for PAP, phase 2) selection of participants, phase 3) evaluation of the participants and phase 4) PAP intervention Phase 4 will be subdivided into 4 subphases: $P_{1}$ ) pre-evaluation, $P_{2}$ ) development of PAP sessions, $\mathrm{P}_{3}$ ) post-evaluation and $\mathrm{P}_{4}$ ) retention measure.

Figure 2. Schedule of enrolment, interventions, and assessments.

\section{Phase 1: Recruitment of the school for PAP}

The PAP is a random longitudinal design of the first part of the study offered to the participating schools. This part of the program aims to develop an out-of-school PA program with the objective of increasing the PA levels of the participants. For the recruitment of the schools, a lottery will be held among the participating high schools of the province of Cáceres. Likewise, a reserve list will be drawn up in case school directors refuse to collaborate in the intervention of the PAP. The raffle will provide a total of four schools in which to carry out the out-of-school PAP. Subsequently, the school directors will be contacted to obtain their approval and develop the extra-curricular PAP in the schools. After confirming their participation, we will begin to recruit the participants through talks, meetings, posters, etc. If not enough 
participants are recruited to develop the out-of-school PAP, the corresponding school of the reserve list will be used. If the school director accepts participation and sufficient participants are available, a new draw will be made among the participating schools to determine their assignation to the experimental group (EG) or control group (CG). There will be 2 EGs and 2 CGs. An initial meeting will be held with all the students interested in participating in the PAP outside school hours to set the days of the week and hours according to the participants' interests. All students who wish to participate must submit two authorizations, one signed by their parents or tutors, and the other signed by the participants themselves, accepting participation in the programme. The out-of-school PAP will be developed during 23 weeks, with a frequency of three weekly 60-minute sessions (see section: intervention program: training periodization)..

\section{Phase 2: Selection of participants}

A total of 120 participants will be enrolled in the out-of-school PAP. Based on previous intervention programs (29-31), the selection of the number of participants for the present investigation is considered to be be adequate. We believe that this sample size is feasible and realistic, based on studies of previous intervention programs. For statistical calculations, we will use IBM - SPSS software (version 23).

The estimates of the sample size and sampling power of the study are based on various observations of studies in which an intervention program based on PA and good habits was carried out $(3,4,29-34)$.

\section{Inclusion criteria}

The intervention will also be implemented for adolescents who are overweight (BMI $\geq 25)$ and obese $(\mathrm{BMI} \geq 30)$, as well as those who are active (time PA $>30 \mathrm{~min}>3$ days/week). The criteria inclusion can be consulted in Table 2.

Excessive increase in levels of overweight and obesity in adolescence is associated with the risk of cardiovascular illness in the future $(8,35)$, which reinforces the need to include this population within the study. In addition, despite the evidence that more active people show higher psychosocial levels $(12,36-$ 38), it has not yet been determined whether increasing the PA levels of already active adolescents may strengthen or even increase psychosocial levels, although this supports the need to also include this group within the research.

This varied inclusion of sedentary, overweight, obese and active students will allow studying the effects produced by PA on the biological and psychosocial variables in both population groups. It has been shown that PA has a direct relationship with biological and psychosocial health, which is higher in active people than in sedentary people $(11,12)$. Therefore, it would be expected that both population groups would improve the parameters related to physical condition, body composition and psychosocial variables. 


\begin{tabular}{ll}
\hline Inclusion criteria & Exclusion criteria \\
\hline Age: 12 - 14 years & $\begin{array}{l}\text { Unwillingness either to complete the study requirements or to be } \\
\text { randomised into control or training group. }\end{array}$ \\
Not participating in a weight loss & \\
programme & \\
Provide informed consent by \\
parents or legal guardians \\
Participants must be capable and \\
willing to provide consent, \\
understand exclusion criteria and \\
accept the randomised group \\
assignment. \\
Participants must attend at least \\
$80 \%$ of the sessions.
\end{tabular}

\section{Retention and adherence of the participants}

Participants may abandon their participation in the study at any time but, to reduce participant dropout and maintain compliance with the program, several strategies will be used (i.e., allowing the participants to freely decide to perform some tasks over others or giving the adolescents responsibility).

All the sessions will be accompanied by the music selected by the participants and will be held in the gym of the corresponding school. Previously, it has been verified that the room in which the out-of-school PAP will take place has optimal ventilation and lighting conditions. Project technicians will carefully supervise each session and work with independent groups of no more than 30 participants to ensure good counselling.

To achieve greater adherence to and engagement in the program and based on the postulates of the SDT (9), methodological and motivational strategies designed with the interests and motivations of young people in mind will be developed to promote and consolidate the practice of out-of-school PA.

Table 3. Training periodization 


\begin{tabular}{|c|c|c|c|c|c|c|}
\hline & & \multicolumn{4}{|c|}{ Training priority } & \\
\hline Phases & Weeks & $\begin{array}{l}\text { Aerobic } \\
\text { training }\end{array}$ & $\begin{array}{l}\text { Strength } \\
\text { training }\end{array}$ & Socialization & Speed & \\
\hline \multirow[t]{4}{*}{ Familiarization } & 1 & & PRE - EV & LUATION & & \\
\hline & 2 & $\mathrm{XX}$ & $\mathrm{X}$ & $\mathrm{XXX}$ & $X$ & \multirow{21}{*}{$\begin{array}{l}\text { DEVELOPMENT OF THE } \\
\text { INTERVENTION PROGRAM }\end{array}$} \\
\hline & 3 & $x$ & $X$ & $X X X$ & $X$ & \\
\hline & 4 & $X X$ & $x$ & $X X$ & $x$ & \\
\hline \multirow[t]{4}{*}{ Month 1} & 5 & $X X$ & $\mathrm{X}$ & $X X$ & $X X$ & \\
\hline & 6 & $X X$ & $X X$ & $X X$ & $\mathrm{X}$ & \\
\hline & 7 & $X X$ & $X X$ & $X X$ & $X X$ & \\
\hline & 8 & $x$ & $X X$ & $X X$ & $x$ & \\
\hline \multirow{4}{*}{ Month 2} & 9 & $\mathrm{X}$ & $x x$ & $x X X$ & $x X$ & \\
\hline & 10 & $X X$ & $\mathrm{XX}$ & $\mathrm{XX}$ & $\mathrm{x}$ & \\
\hline & 11 & $X X$ & $\mathrm{X}$ & $X X$ & $X X$ & \\
\hline & 12 & $X X$ & $\mathrm{X}$ & $X X$ & $\mathrm{X}$ & \\
\hline \multirow[t]{5}{*}{ Month 3} & 13 & $x$ & $x$ & $X X$ & $X X$ & \\
\hline & 14 & $x$ & $X X$ & $X X$ & $\mathrm{X}$ & \\
\hline & 15 & $X X$ & $X X$ & $\mathrm{XX}$ & $\mathrm{XX}$ & \\
\hline & 16 & $X X$ & $\mathrm{x}$ & $X X$ & $\mathrm{X}$ & \\
\hline & 17 & $x$ & $X X$ & $X X$ & $x$ & \\
\hline \multirow[t]{6}{*}{ Month 4} & 18 & $X$ & $\mathrm{X}$ & $X X X$ & $X X$ & \\
\hline & 19 & $\mathrm{X}$ & $X X$ & $X X$ & $\mathrm{X}$ & \\
\hline & 20 & $X X$ & $\mathrm{X}$ & $X X$ & $X$ & \\
\hline & 21 & $X X$ & $x$ & $X X$ & $x$ & \\
\hline & 22 & $\mathrm{x}$ & $\mathrm{X}$ & $\mathrm{XXX}$ & $\mathrm{x}$ & \\
\hline & 23 & \multicolumn{4}{|c|}{ POST - EVALUATION } & \\
\hline \multicolumn{2}{|l|}{$\begin{array}{c}3 \text { months } \\
\text { later }\end{array}$} & \multicolumn{4}{|c|}{ RETENTION EVALUATION } & \\
\hline
\end{tabular}

Note. $\mathrm{X}$ : Low priority; $\mathrm{XX}=$ Medium priority; $\mathrm{XXX}=$ High priority

\section{Phase 3: Evaluation of the participants}

The out-of-school PAP will create collaborative learning so participants will achieve improvements at the social, psychological, physical and anthropometric level, in addition to increasing their PA levels. To support the development of this program, an implementation team will be designated to carry out the activities, which will vary according to the time and interest of the participants.

\section{Evaluation of the CG}

The control group will be selected in a targeted manner according to the availability of the school. The same package of questionnaires and anthropometric and physical tests will be given to them as to the EG. They will not be given any information about healthy habits nor will any physical training program be 
applied to them, so that they do not receive indications that could produce a variation of their habitual behavior.

\section{Evaluation of the EG}

In addition to the variables and instruments that will be used for the cross-sectional evaluation (consult the section of the variables and instruments of the cross-sectional part), in the PAP will be included (see Table 4):

PA objective information. The ActiGraph accelerometer model GT3X + (Actigraph TM, LLC, Fort Walton Beach, FL, USA) is used to obtain detailed and objective information about daily PA and sedentary behaviour over seven consecutive days. Previous studies have revealed strong agreement between measures from GT3X + activity monitors without needing additional calibration $(39,40)$, and have reported that these instruments are technically reliable (41). The accelerometer is attached tightly at the back of the hip, with the notch facing upwards, and participants are instructed to use the accelerometer during waking hours and remove it during water-based activities and when sleeping, according to established procedures (42). The epoch length is analyzed to 10 seconds to allow a more detailed estimate of PA intensity. The screening and data processing procedures to estimate sedentary time, total $\mathrm{PA}$, and PA at different intensities are consistent with previous studies in children and adolescents $(42,43)$.

Self-Esteem. The Spanish version of the Rosenberg Self-Esteem Scale (RSE) (44) will be used. The RSE (Rosenberg, 1965) is a 10-item self-report questionnaire assessing global self-esteem. Items are scored from 1 to 4 ( 1 = strongly agree, 2 = agree, 3 = disagree, $4=$ strongly disagree),, and it is thought to represent a single trait of global self-esteem (33). Five items are negatively worded (numbers 3, 5, 8, 9, and 10) and five items are positively worded.

Bullying. To evaluate bullying, theEuropean Bullying Intervention Project Questionnaire (EBIPQ) (45) will be used. Its objective is to measure the prevalence of bullying. This measure includes the basic question "Have you participated in the following behavior in the last 2 months?" Followed by 14 items, for example, "I hit, kicked or pushed someone, or excluded or ignored someone". Answers are recorded on a 5-point Likert scale $(0=n o, 1=y e s$, once or twice, $2=$ yes, once or twice a month, $3=$ yes, about once a week, $4=$ yes, more than once a week)..

Cyberbullying. To examine cyberbullying, theEuropean Cyberbullying Intervention Project Questionnaire (ECIPQ) (46) will be used. This questionnaire aims to evaluate the different types of behaviors and actions that define cyberbullying. It consists of two dimensions: cyber-victimization and cyberaggression. This questionnaire includes the basic question "Have you participated in the following behavior, either online or through mobile phones in the last 2 months?" The instrument is composed of 22 items, rated a 5-point Likert scale ranging from 0 (never) to 4 (always).. The items refer to actions such as excluding someone or spreading rumors, impersonating someone's identity... all of them electronic. 
Regulation of Behavior in Physical Exercise. To evaluate the students' underlying motivational regulation towards participation, the 19-item Behavioural Regulation in Exercise Questionnaire (BREQ-2) (47) will be conducted. It comprises five regulation or motivational subscales: (1) Intrinsic, (2) Identified, (3) Introjected, (4) External, and (5) Amotivation. Responses were made on a 5-point Likert scale with verbal anchors affixed to ' 0 ' (Not true for me), '2' (Sometimes true for me) and '4' (Very true for me) (48). The Relative Autonomy Index (RAI) is a composite score used to indicate the degree to which a person's exercise motivation is intrinsic or self-determined. The RAl is calculated by multiplying each Behavioural Regulation subscale score by a specific weight, and then summing the weighted scores. The maximum score for the RAl is +20 , whereas the minimum is -24 , with higher positive scores indicating more intrinsic motivation (10). For example, Item 1 is an External Regulation statement ( -2 weight) "I exercise because people say I should." If the respondent chooses 2 (on a scale of $0-4$ ), the score (2) is multiplied by the weight $(-2)$, obtaining a score of -4 for this item.

Satisfaction with life. This aspect was evaluated with the Satisfaction With Life Scale (SWLS, (49)). The scale has 5 items rated on a 5-point Likert scale, ranging from 1 (Totally disagree) to 5 (totally agree). The present investigation will use to Spanish version of the SWLS (50).

Positive and negative affect. The Positive and Negative Affect Schedule (PANAS) (51) presents 10 adjectives that reflect positive affect (e.g., interested) and 10 adjectives that represent negative affect (e.g., distressed). Positive and negative adjectives were mixed and presented in two columns, as shown by Watson et al. (51). Participants rated each adjective on a 5-point scale ranging from 1 (very slightly or not at all) to 5(extremely)..

Table 4. PAP variables

\begin{tabular}{ll}
\hline \multicolumn{1}{c}{ Variable } & \multicolumn{1}{c}{ Instrument } \\
\hline Lifestyle variables + & Health-related fitness (Table 1) \\
\hline PA objective information & ActiGraph model GT3X + \\
\hline Self-Esteem & RSE (44) \\
\hline Bullying & EBIPQ (45) \\
\hline Cyberbullying & ECIPQ (46) \\
\hline Regulation of Behavior in Physical Exercise & BREQ-2 (47) \\
\hline Satisfaction with Life & SWLS (49) \\
\hline Positive and negative affectiv & PANAS (51) \\
\hline
\end{tabular}

\section{Phase 4: PAP intervention}

The intervention program will last 23 weeks, which were divided into three large blocks:

Pre-evaluation. It will last a week. Throughout this phase, we will carry out an initial evaluation of the variables included in the PAP, to establish an initial starting point of the participants in the psychosocial, 
anthropometric and physiological variables.

Development of PAP sessions. This will last 21 weeks. Numerous cooperative, continuous activities will be carried out to develop the basic physical capacities: strength, endurance, speed and flexibility.

Post-evaluation. This will last 1 week. A final evaluation will be performed (same variables and instruments as in the initial evaluation) in order to compare them with the initial values and assess the effects produced by the PAP.

Retention measure. Transcription and analysis of the data. This will be performed 3 months after the PAP in order to know the effects produced over time. It will last for 3 weeks, during which the members of the EG and CG will be re-evaluated.

\section{Justification of the PAP and dosis selection}

With the ultimate goal of making the exercise program transferable to society, the basis and design of the PAP will comply with the recommendations proposed by the WHO [1]. Following the line of similar previous studies, the PAP will combine both aerobic and strength training. An important objective of the study is to assess adolescents' PA levels to determine whether they meet the values standardised by the WHO [1] and whether the PA levels of the EG outside the PAP increased compared to those of the CG, and to determine whether that behavior is maintained over time.

Trial duration will be five months, given the results of a RCT conducted previously with adolescents within the school environment. (29). Considering the increase in logistical and participation loads that could lead to poor adherence to PAP, as well as the cost of conducting a highly controlled study in a laboratory for a long time, the sessions of the intervention program will be given inside the gym of the corresponding school.

\section{PAP volume}

In order to make the results of the study easily transferable and understandable to the population in terms of time in minutes/week, intensity, and frequency, the recommendations of the PA level established by the WHO will be followed [1], so that three 60 -minute sessions of mainly aerobic PA will be established.

It is estimated that $150 \mathrm{~min} /$ week of moderate intensity aerobic exercise $( \pm 3-5.9$ metabolic equivalents [MET, $1 \mathrm{MET}=3.5 \mathrm{ml} \mathrm{O} / 2 / \mathrm{kg} / \mathrm{min}$ ]) equals $1000 \mathrm{kcal} /$ week, which is associated with lower rates of cardiovascular disease and premature mortality (52). Therefore, the participants will establis this frequency and duration will accumulate the indicated of metabolic equivalents, obtaining such benefits for their health. An energy expenditure of $1000 \mathrm{kcal} /$ week cal also be achieved with $\pm 75 \mathrm{~min} /$ week of vigorous intensity exericse ( $\geq 6 \mathrm{MET}$ ). 


\section{PAP frecuency}

Studies on the frequency of exercise show small differences for 3 or more days a week, provided that the weekly dose of exercise is reached (52). Therefore, depending on the availability of the participants, a total of 3 weekly sessions will be established. Participants will be advised to attend all PA sessions. The participants will be contacted when they miss a scheduled session to request them to perform an aerobic PA session, following the recommendations of the PAP researchers.

\section{Type of exercise of the PAP}

The activities of the aerobic exercise program will be developed by the PAP researchers. In all the sessions, basic physical skills will be addressed: strength, endurance, speed and flexibility, as well as the motor capacities of coordination and balance. The dynamics of these sessions will be the establishment of "continuous activities carried out", with playful proposals, focused on the improvement of physical and psychosocial parameters.

The SDT postualates three basic psychological needs: competence (the desire to interact effectively with the environment), autonomy (the desire to choose freely and the feeling of being the initiator of one's actions) and relatedness (the desire to feel connected to respected by others). It also postulates that the satisfaction of these needs is essential for the development of self-determined motivation (53) and psychological well-being (9). The social environment plays an important role in the satisfaction or thwarting of these needs. When authority figures support participants' autonomy, offering freedom and favoring participants' involvement in the decision-making process, then the basic psychological needs of autonomy, competence and relatedness are fulfilled. However, when these figures use a controlling style, acting coercively, exerting pressure, and behaving authoritatively, these needs are frustrated. Support of the basic psychological needs promotes more intrinsic and self-determined motives in task performance, increasing people's welfare (9). Taking this into account and to prevent dropout and need thwarting, and thus increase autonomy, competence and relatedness, the PAP will not be a closed program, but instead, participants' interests will be taken into account at all times, adapting the exercise and activities to participants' demands.

\section{Variation of the PAP training load}

We are aware that participants may not be immediately capable of physical exercise at the required dose of volume and intensity. Therefore, there will be a gradual progression to the training load. In addition, in view of the psychosocial benefits, the first sessions of the PAP will be used to encourage the participants' socialization.

\section{Statistical analysis}


The confidentiality of the data will be maintained at all times, since each student will be assigned a corresponding code, thus blinding the researcher who will process the database. The missing data, either due to dropout or non-compliance with the inclusion criteria established for the out-of-school PAP (attendance $\geq 80$ ), will be treated using multiple methods of imputation, in accordance with the principle of Hollar et al. [54]. The normality of the variables will be verified and the results expressed as means, standard deviation, medians or different ranges. To evaluate possible predictors, multiple regression analysis will be performed on the independent variables of sedentary lifestyle, PA, anthropometric variables or health-related fitness and psychosocial variables. The comparisons between groups (EG vs. $\mathrm{CG}$ ) of the continuous variables will be analyzed by means of analysis of variances or the nonparametric Kruskall-Wallis method, as well as Chi-squared tests, as appropriate. General linear models such as ANOVA, UNIANOVA, MANOVA, etc. will also be used to evaluate the effects of training among groups. Finally, mediation or moderation analyses will be conducted as appropriate, using the PROCESS macro for SPSS.

\section{Discussion}

Potential impact of the multidisciplinary program for the promotion of PA and healthy habits in adolescents

This project contributes to one of the most important social challenges, taking into account the socioeconomic impact that it will generate in Extremadura, as well as its potential to apply the results and transfer them to the productive sector. This project is of great interest to the scientific community as it will provide relevant information on IP issues, sedentary lifestyle, generation of healthy habits and physical exercise. PA seems to play a key role in the prevention and treatment of sedentary lifestyle and IP, and directly affects the prevention and treatment of overweight and obesity, as well as the improvement of body image, motivation toward PA, self-concept, satisfaction with life, etc., All this undoubtedly generates better performance in other aspects, such as school, future work or the acquisition of healthy habits, and has a high impact on the participants.

Related to the impact of the project, we propose to train teachers and monitors in appropriate motivational strategies to increase adherence to the practice of PA in society. The increase of PA would lead to a decrease in public expenditure to alleviate the consequences caused by $\mathrm{Pl}$, as only one disease such as obesity, represents $7 \%$ of the expenditure of the Spanish National Health System, equal to $0.6 \%$ of Gross Domestic Product. In fact, in the "I Healthy Habits Day", held in Madrid in July, 2013, it was estimated that, for every euro that public administrations invest in the promotion and promotion of PA, a saving of 15 euros for health institutions is produced. That is, investment in the practice of PA not only benefits the population, but also leads to economic saving for the public institutions. Hence, the performance of PA by adolescents who were rather sedentary leads to a short-, medium- and long-term saving for the public administration. 
This study integrates three different disciplines, the physiology of exercise, sports psychology and psychosocial consequences of sport in adolescents, to determine whether exercise can: (i) improve the levels of PA in adolescents through the design, development and evaluation of a multidisciplinary PA intervention program to promote healthier lifestyles; (ii) increase the levels of PA practice, and psychosocial and anthropometric variables among the EG adolescent participants, compared to the CG participants; and (iii) generate lasting healthy habits among the participants in the intervention program.

Exercise intervention can potentially translate into a moderate but "chronic" increase in total energy expenditure. Therefore, even if the PAP does not produce significant improvements in the psychosocial, anthropometric or physical variables, it could play a compensatory role of exercise and its protective effects against the development of overweight and obesity, as well as promote participants' social relationships.

\section{Declarations}

Ethics approval and consent to participate: Declaration of Helsinki, and its 2013 modification, and approved by the Human Research Ethics Committee of the University of Extremadura.

Consent for publication: no apply.

Availability of data and materials: no apply.

Competing interests: the authors declare that they have no competing interests

Funding: Ministry of Economy and Infrastructures, by the University of Extremadura and funds of the European Union

Authors' contributions: S.M: design, instrument selection and manuscript preparation, V.S: data collection and review of the manuscript, S.O: design and instrument selection P: date recollection T.S: data collection and manuscript preparation.

Acknowledgements: the present investigation is a Research Project in the Public I + D I Centers of the Autonomous Community of Extremadura (IB16193), supported by the Ministry of Economy and Infrastructures, by the University of Extremadura and funds of the European Union. Also thank the voluntary and selfless involvement of secondary schools in the region, who hope that at all times show interest in the project we intend to develop. It will also be necessary to thank all the researchers involved, who will be responsible for exploiting the database generated from this project. The order of the authors of the publications derived from the project will vary depending on the degree of involvement of each researcher. In addition, by not using professional editors, the dedicated effort will be made during the preparation of each manuscript.

\section{List Of Abbreviations}


PAP: Physical Activity Programme

PA: Physical Activity

SDT: Self-Determination Theory

Pl: Physical Inactivity

\section{References}

1. WHO. Recomendaciones mundiales sobre actividad física para la salud; (2010); Vol. Suiza

2. NCD Risk Factor Collaboration Worldwide trends in body-mass index, underweight, overweight, and obesity from 1975 to 2016: a pooled analysis of 2416 population-based measurement studies in $128 \cdot 9$ million children, adolescents, and adults. Lancet (2017), 390, 2627-2642.

3. Ericsson, I. Effects of increased physical activity on motor skills and marks in physical education: an intervention study in school years 1 through 9 in Sweden. Phys. Educ. Sport Pedagog. (2011), 16, 313-329.

4. Faigenbaum, A.D.; Gipson-Jones, T. L.; Myer, G. D. Exercise Deficit Disorder in Youth. J. Sch. Nurs. (2012), 28, 252-255.

5. Pinto, S. M. P.; Power, C. Change in health and social factors in mid-adulthood and corresponding changes in leisure-time physical inactivity in a prospective cohort. Int. J. Behav. Nutr. Phys. Act. (2018), 15, 89.

6. Guthold, R.; Stevens, G. A.; Riley, L. M.; Bull, F. C. Worldwide trends in insufficient physical activity from 2001 to 2016: a pooled analysis of 358 population-based surveys with 1.9 million participants. Lancet Glob. Heal. (2018), 6, e1077-e1086.

7. García-Ferrando, M. Postmodernidad y deporte: Entre la individualización y la masificación: encuesta sobre hábitos deportivos de los españoles. CIS (2005), 38.

8. Ong, K. K.; Ahmed, M. L.; Dunger, D. B. Lessons from large population studies on timing and tempo of puberty (secular trends and relation to body size): The European trend. Mol. Cell. Endocrinol. (2006), 25, 254-255.

9. Deci, E. L.; Ryan, R. M. The "What" and "Why" of Goal Pursuits: Human Needs and the SelfDetermination of Behavior. Psychol. Inq. (2000), 11, 227-268.

10. Teixeira, P. J.; Carraça, E. V; Markland, D.; Silva, M. N.; Ryan, R. M. Exercise, physical activity, and selfdetermination theory: A systematic review. Int. J. Behav. Nutr. Phys. Act. (2012), 9, 78.

11. Proietto, J.; Baur, L. A.; Chisholm, D. J.; Zajac, J. D.; Edward, S. Management of obesity; (2004); Vol. 180;.

12. Biddle, S.; Fox, K. R.; Boutcher, S. H. Physical activity and psychological well-being. (2000).

13. Kowalski, K.; Crocker, P.; Donen, R. Physical Activity Questionnaire for Adolescents. (2013). 
14. Martínez-Gómez, D.; Martínez-de-Haro, V.; Pozo, T.; Welk, G. J.; Villagra, A.; Calle, M. E.; Marcos, A.; Veiga, O. L. Fiabilidad y validez del cuestionario de actividad física PAQ-A en adolescentes españoles. Rev. Esp. Salud Publica (2009), 83, 427-439.

15. Telama, R. Decline of Physical Activity from Youth to Young Adulthood in Finland Determinants of sedentary behavior at different phases of life-identifying barriers to physically active lifestyles View project Exercise for the Prevention of Low Back Pain View project. (2000).

16. Cabanas-Sánchez, V.; Martínez-Gómez, D.; Esteban-Cornejo, I.; Castro-Piñero, J.; Conde-Caveda, J.; Veiga, Ó.L. Reliability and validity of the Youth Leisure-time Sedentary Behavior Questionnaire (YLSBQ). J. Sci. Med. Sport (2018), 21, 69-74.

17. Segura-García, C.; Papaianni, M. C.; Rizza, P.; Flora, S.; Fazio, P. De The development and validation of the Body Image Dimensional Assessment (BIDA). Eat. Weight Disord. - Stud. Anorexia, Bulim. Obes. (2012), 17, e219-e225.

18. Serra-Majem, L.; Ribas, L.; Ngo, J.; Ortega, R. M.; García, A.; Pérez-Rodrigo, C.; Aranceta, J. Food, youth and the Mediterranean diet in Spain. Development of KIDMED, Mediterranean Diet Quality Index in children and adolescents. Public Health Nutr. (2004), 7, 931-935.

19. Ruíz, J. R.; España Romero, V.; Castro Piñero, J.; Artero, E. G.; Ortega, F. B.; Cuenca García, M.; Jiménez Pavón, D.; Chillón, P.; Girela Rejón, M. J.; Mora, J.; et al. Batería ALPHA-Fitness: test de campo para la evaluación de la condición física relacionada con la salud en niños y adolescentes. SciELO Espana (2011), 26, 1210-1214.

20. Lohman, T..; Roche, A. F.; Matorell, R. Anthropometric standardization reference manual. Hum. Kinet. (1991).

21. Slaughter, M.; Lohman, T.; Boileau, R.; Horswill, C.; Stillman, R.; Loan, V.; Bemben, D. Skinfold Equations for Estimation of Body Fatness in Children. Biology (Basel). (1988), 60, 709-723.

22. Nagy, E.; Vicente-Rodriguez, G.; Manios, Y.; Béghin, L.; Iliescu, C.; Censi, L.; Dietrich, S.; Ortega, F. B.; De Vriendt, T.; Plada, M.; et al. Harmonization process and reliability assessment of anthropometric measurements in a multicenter study in adolescents. Int. J. Obes. (2008), 32, S58-S65.

23. España-Romero, V.; Ortega, F. B.; Vicente-Rodríguez, G.; Artero, E. G.; Rey, J. P.; Ruiz, J. R. Elbow Position Affects Handgrip Strength in Adolescents: Validity and Reliability of Jamar, DynEx, and TKK Dynamometers. J. Strength Cond. Res. (2010), 24, 272-277.

24. España-Romero, V.; Artero, E. G.; Santaliestra-Pasias, A.M.; Gutierrez, A.; Castillo, M. J.; Ruiz, J. R. Hand Span Influences Optimal Grip Span in Boys and Girls Aged 6 to 12 Years. J. Hand Surg. Am. (2008), 33, 378-384.

25. Ruiz, J. R.; España-Romero, V.; Ortega, F. B.; Sjöström, M.; Castillo, M. J.; Gutierrez, A. Hand Span Influences Optimal Grip Span in Male and Female Teenagers. J. Hand Surg. Am. (2006), 31, 13671372.

26. Castro-Piñero, J.; Carbonell-Baeza, A.; Martinez-Gomez, D.; Gómez-Martínez, S.; Cabanas-Sánchez, V.; Santiago, C.; Veses, A.M.; Bandrés, F.; Gonzalez-Galo, A.; Gomez-Gallego, F.; et al. Follow-up in healthy schoolchildren and in adolescents with DOWN syndrome: psycho-environmental and genetic 
determinants of physical activity and its impact on fitness, cardiovascular diseases, inflammatory biomarkers and mental health; the UP\&amp;DOWN Study; (2014)

27. Biddle, S.; Gorely, T.; Marshall, S. J.; Cameron, N. The prevalence of sedentary behavior and physical activity in leisure time: A study of Scottish adolescents using ecological momentary assessment. Prev. Med. (Baltim). (2009), 48, 151-155.

28. Ruiz, J. R.; Castro-Piñero, J.; España-Romero, V.; Artero, E. G.; Ortega, F. B.; Cuenca, M. M.; JimenezPavón, D.; Chillón, P.; Girela-Rejón, M. J.; Mora, J.; et al. Field-based fitness assessment in young people: the ALPHA health-related fitness test battery for children and adolescents. Br. J. Sports Med. (2011), 45, 518-24.

29. Ardoy, D. N.; Fernández-Rodríguez, J. M.; Ruiz, J. R.; Chillón, P.; España-Romero, V.; Castillo, M. J.; Ortega, F. B.; Fernández-Rodríguez; J. M., Ruiz, J. R.; Chillón, P.; et al. Improving Physical Fitness in Adolescents Through a School-Based Intervention: the EDUFIT Study. Rev. Española Cardiol. English Ed. (2011), 64, 484-491.

30. González-Gross, M.; Ruiz, J. R.; Moreno, L. A.; de Rufino-Rivas, P.; Garaulet, M.; Mesana, M. I.; Gutiérrez, A.; AVENAGroup*, T. Body composition and physical performance of Spanish adolescents: the AVENA pilot study. Acta Diabetol. (2003), 40, s299-s301.

31. Naylor, P.-J. P. J.; Macdonald, H. M.; Zebedee, J. A.; Reed, K. E.; McKay, H. A. Lessons learned from Action Schools! BC-an 'active school'model to promote physical activity in elementary schools. J. Sci. Med. Sport (2006), 9, 413-423.

32. Quaresma, A.M.; Palmeira, A. L.; Martins, S. S.; Minderico, C. S.; Sardinha, L. B. Effect of a schoolbased intervention on physical activity and quality of life through serial mediation of social support and exercise motivation: the PESSOA program. Health Educ. Res. (2014), 29, 906-917.

33. Pardo, B. M.; Bengoechea, E. G.; Julián Clemente, J. A.; Lanaspa, E. G. Empowering adolescents to be physically active: Three-year results of the Sigue la Huella intervention. Prev. Med. (Baltim). (2014), $66,6-11$.

34. Europea, U. Directrices de actividad física de UE. Traducción e impresión Cons. Super. Deport. Madrid CSD. (2008).

35. Martínez-Vizcaino, V.; Mota, J.; Solera-Martínez, M.; Notario-Pacheco, B.; Arias-Palencia, N.; GarcíaPrieto, J. C.; González-García, A.; Álvarez-Bueno, C.; Sánchez-López, M. Rationale and methods of a randomised cross-over cluster trial to assess the effectiveness of MOVI-KIDS on preventing obesity in pre-schoolers. Biomed Cent. Public Heal. (2015), 15, 176.

36. Lawlor, D. A.; Hopker, S. W. The effectiveness of exercise as an intervention in the management of depression: systematic review and meta-regression analysis of randomised controlled trials. BMJ (2001), 322, 763.

37. Ruiz, J. R.; Castro-Piñero, J.; Artero, E. G.; Ortega, F. B.; Sjöström, M.; Suni, J.; Castillo, M. J. Predictive validity of health-related fitness in youth: a systematic review. Br. J. Sports Med. (2009), 43, 909923. 
38. Stubbe, J. H.; de Moor, M. H. M.; Boomsma, D. I.; de Geus, E. J. C. The association between exercise participation and well-being: A co-twin study. Prev. Med. (Baltim). (2007), 44, 148-152.

39. Robusto, K. M.; Trost, S. G. Comparison of three generations of ActiGraphTM activity monitors in children and adolescents. J. Sports Sci. (2012), 30, 1429-1435.

40. Vanhelst, J.; Mikulovic, J.; Bui-Xuan, G.; Dieu, O.; Blondeau, T.; Fardy, P.; Béghin, L. Comparison of two ActiGraph accelerometer generations in the assessment of physical activity in free living conditions. BMC Res. Notes (2012), 5, 187.

41. Rothney, M. P.; Apker, G. A.; Song, Y.; Chen, K. Y. Comparing the performance of three generations of ActiGraph accelerometers. J. Appl. Physiol. (2008), 105, 1091-1097.

42. Ward, D. S.; Evenson, K. R.; Vaughn, A.; Rodgers, A. B.; Troiano, R. P. Accelerometer use in physical activity: best practices and research recommendations. Med. Sci. Sports Exerc. (2005), 37, S582-8.

43. Ortega, F. B.; Konstabel, K.; Pasquali, E.; Ruiz, J. R.; Hurtig-Wennlöf, A.; Mäestu, J.; Löf, M.; Harro, J.; Bellocco, R.; Labayen, I.; et al. Objectively Measured Physical Activity and Sedentary Time during Childhood, Adolescence and Young Adulthood: A Cohort Study. PLoS One (2013), 8, e60871.

44. Vázquez, A. J.; Rosa, M.; García-Bóveda, J. Escala de autoestima de Rosenberg: fiabilidad y validez en población clínica española. Col. Ofi cial Psicol. (2004), 22, 247-255.

45. Brighi, A.; Ortega, R.; Scheitauer, H.; Smith, P. K.; Tsormpatzoudis, C., Barkoukis, V.; Del Rey, R. European bullying intervention project questionnaire (EBIPQ). Univ. Bol. (2012).

46. Del Rey, R.; Casas, J. A.; Ortega-Ruiz, R.; Schultze-Krumbholz, A.; Scheithauer, H.; Smith, P.; Thompson, F.; Barkoukis, V.; Tsorbatzoudis, H.; Brighi, A.; et al. Structural validation and cross-cultural robustness of the European Cyberbullying Intervention Project Questionnaire. Comput. Human Behav. (2015), 50, $141-147$.

47. Markland, D.; Tobin, V. A Modification to the Behavioural Regulation in Exercise Questionnaire to Include an Assessment of Amotivation A Modification to the Behavioural Regulation in Exercise Questionnaire to Include an Assessment of Amotivation. (2004).

48. Wilson, P.M.; Sabiston, C. M.; Mack, D. E.; Blanchard, C. M. On the nature and function of scoring protocols used in exercise motivation research: An empirical study of the behavioral regulation in exercise questionnaire. Psychol. Sport Exerc. (2012), 13, 614-622.

49. Diener, E.; Eunkook, M. S.; Richard, E. L.; Heidi, L. S. Subjective Well-Being: Three Decades of Progress. Psychol. Bull. (1984), 95, 542-575.

50. Atienza, F.; Balaguer, I.; García-Merita, M. Psicothema. Propiedades Psicométricas de la Escala de Satisfacción con la Vida en Adolescentes (2000).

51. Watson, D.; Clark, L. A. L. A.; Tellegen, A. Development and Validation of Brief Measures of Positive and Negative Affect. The PANAS Scales (1988), 54, 1063-1070.

52. Garber, C. E.; Blissmer, B.; Deschenes, M. R.; Franklin, B. A.; Lamonte, M. J.; Lee, I.-M.; Nieman, D.C.; Swain, D. P.; American College of Sports Medicine American College of Sports Medicine position stand. Quantity and quality of exercise for developing and maintaining cardiorespiratory, 
musculoskeletal, and neuromotor fitness in apparently healthy adults: guidance for prescribing exercise. Med. Sci. Sports Exerc. (2011), 43, 1334-59.

53. Deci, E. L.; Ryan, R. M. Intrinsic motivation and self-determination in human behavior; New York, (1985)

54. Hollar, D.; Messiah, S. E.; Lopez-Mitnik, G.; Hollar, T. L.; Almon, M.; Agatston, A. S. Healthier Options for Public Schoolchildren Program Improves Weight and Blood Pressure in 6- to 13-Year-Olds. J. Am. Diet. Assoc. (2010), 110, 261-267.

\section{Figures}
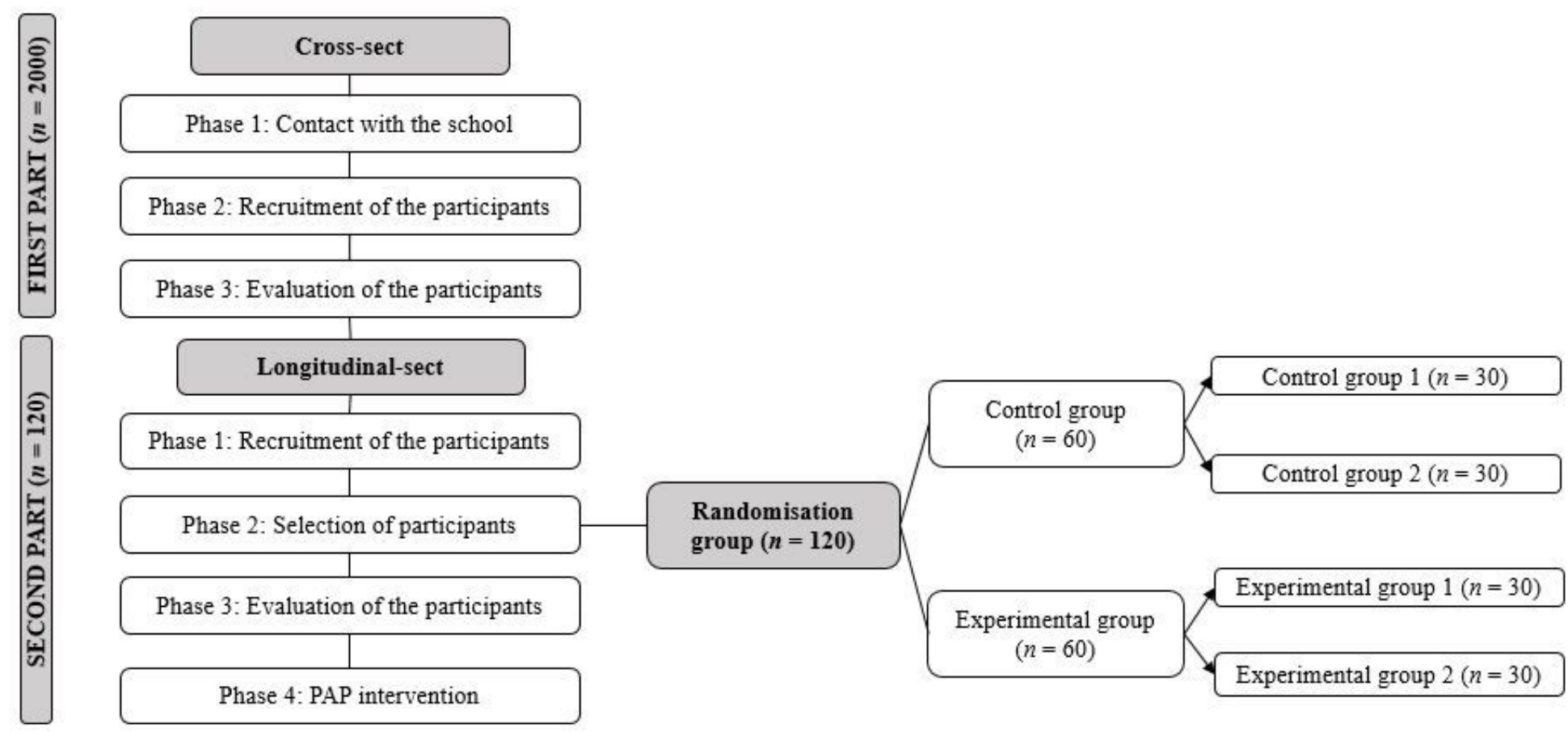

Figure 1

Programme design 


\begin{tabular}{|c|c|c|c|c|c|c|c|c|}
\hline \multirow[b]{3}{*}{ TIMEPOINT $^{* *}$} & \multicolumn{7}{|c|}{ PAP } & \multirow{3}{*}{$\begin{array}{c}\text { Close-ou } \\
P_{4} \\
\end{array}$} \\
\hline & \multirow{2}{*}{$\begin{array}{c}\text { Enrolment } \\
\text { Phase } 1 \\
\end{array}$} & \multicolumn{2}{|c|}{ Allocation } & \multicolumn{4}{|c|}{ Post-allocation } & \\
\hline & & Phase 2 & Phase 3 & $P_{1}$ & $\boldsymbol{P}_{2}$ & $P_{3}$ & $P_{4}$ & \\
\hline \multicolumn{9}{|l|}{ ENROLMENT: } \\
\hline \multirow{3}{*}{$\begin{array}{l}\text { Eligibility screen } \\
\text { Informed consent } \\
\text { [List other procedures] }\end{array}$} & $\mathrm{x}$ & & & & & & & \\
\hline & $\mathrm{x}$ & & & & & & & \\
\hline & $\mathrm{X}$ & & & & & & & \\
\hline \multicolumn{9}{|l|}{ Allocation } \\
\hline \multicolumn{9}{|l|}{ INTERVENTIONS: } \\
\hline \multicolumn{9}{|l|}{ Control Group } \\
\hline \multicolumn{9}{|l|}{ Experimental Group } \\
\hline \multicolumn{9}{|l|}{ ASSESSMENTS: } \\
\hline \multirow{3}{*}{$\begin{array}{r}\text { [List baseline } \\
\text { variables] } \\
\text { [List outcome } \\
\text { variables] } \\
\text { [List other data } \\
\text { variables] }\end{array}$} & & $\mathrm{x}$ & $\mathrm{x}$ & $\mathrm{x}$ & & $\mathrm{x}$ & $\mathrm{x}$ & \\
\hline & & & & & $\mathrm{X}$ & $\mathrm{x}$ & $\mathrm{X}$ & $\mathrm{x}$ \\
\hline & & & & $\mathrm{x}$ & $\mathrm{x}$ & $\mathrm{x}$ & $\mathrm{X}$ & $\mathrm{X}$ \\
\hline
\end{tabular}

Figure 2

Schedule of enrolment, interventions, and assessments.

\section{Supplementary Files}

This is a list of supplementary files associated with this preprint. Click to download.

- SPIRITChecklist.doc 